\title{
MEDICAL LITERATURE AND MEDICAL LIBRARIES.
}

\author{
By WALTER A. JAYNE, M.D. \\ Metropolitan Building, Denver, Colorado.
}

Medical literature is a specialty and should be so treated in all library work, at least it is only when it receives the particular care and attention of one who is acquainted with it that it attracts medical men and attains its greatest usefulness. Otherwise it lies dormant on the shelves, it is used in a desultory manner and mainly by the general public, or accumulates the dust of neglect. With the hope of emphasizing the special care that this branch of literature should receive, and advance its proper library treatment. I have gathered together for your consideration a few facts pertaining to the development and growth of medical literature and medical libraries. Such an historical sketch as I may present must necessarily be a brief and cursory one but I trust you may find in it something of interest to reward the attention you may give it.

Medicine, using the term in its broad sense, is in the forefront of progress among the sciences. Discoveries made barely more than a generation ago that germ life is the cause of all infectious diseases and developments in biological chemistry have shed so much light on all disease processes that our views and practice have undergone very radical changes and medicine is being placed upon a high scientific plane. Many of its problems are as demonstrable as a theorem of geometry. Diagnoses and treatment are no longer made at the bedside only, but rather upon the collective evidence gained by methods and instruments of precision combined with many chemical and biological tests. A generation ago the medical laboratory as an aid and guide to the practitioner was unknown, today it is indispensable.

It is less than a hundred years since the first laboratories, other than for anatomy, were established for systematic study, by Purkinje at Breslau for physiology (1824), and by Liebig at Giessen for organic chenistry (1826). Now medical research laboratories are established in every civilized country and in many out-of-the-way places for special studies. The few medical investigators of thirty

Read at the Annual Meeting of the Medical L,ibrary Association, Detroit, Michigan, June $12,1916$. 
years ago have been multiplied and today thousands of the best trained minds are devoted to the pure science of medicine. Laboratories are the centers from which come the advanced thought that directs the more scientific activities of practitioners and enable them to attain greater accuracy in diagnosis, greater efficiency in the prevention and cure of disease.

The many achievements of recent years are a source of pride and satisfaction to all medical men, but if we would estimate them correctly and keep our true bearings for future progress we must study the past and appreciate that the late developments in medical as in all other sciences have been made possible only by the long, weary toil of those who have gone before and carefully garnering crumbs of knowledge preserved them for the use of future generations. The results of today are but the culmination of all efforts of all time, the benefits of which we reap; the blossom on the tenderly nutured century plant we are privileged to enjoy.

Looking backward therefore and tracing the rivulets of knowledge to their source we arrive at the dawn of history, the legendary periods of Babylon, Assyria, Greece and Egypt-the oracles, soothsayers, priests and mysteries of the temples - the early forms of recorded knowledge, cuneiform tracings on clay, papyri and manuscripts containing the observations and reflections of physician-philosophers revered through all ages. To the treasured lore of these early days preserved to us by the librarians of old-the dignity of whose office was such that it was on occasion claimed as a prerogative by those of royal blood-in caverns awaiting the modern pick and shovel of Layard or in collections enriched and enlarged by the more acute intellects of succeeding ages-we must look for the early inspiration and practices of medical men. Much of this ancient literature has been lost but a goodly portion has been jealously guarded from disaster by fire, war, the ravaging hand of ignorance and the destructive elements of time and has come to us as a legacy in forms that leave no doubt of genuineness.

Medicine and philosophy were closely interwoven during the classical days of Greece and though knowledge was not specialized it is claimed that medical libraries existed at that time distinct from general collections. We know that one of the two great medical schools of Greece, that at Cnidus, was possessed of a medical library, and probably that of its great rival at Cos, famed as the home of the "Father of Medicine," had an equal equipment. Aristotle is credited as being the first person to collect a library, and as he was an Asclepiad and wrote on medicine it was doubtless largely medical. The great 
libraries at Alexandria were rich in medical manuscripts and each of the many libraries established at Rome and in her provinces had its proportion of medical works. Very much of all this was lost in the fires and general destruction during the fall of the Western empire and that which escaped was scattered, some of it finding its way to Constantinople where large collections were finally gathered. Well authenticated writings of Hippocrates (5th century B. C.) were preserved and have been handed down to us though the greater part of the work attributed to him, the "Collection Hippocrates," should be ascribed to his school as a composite expression of the observations and opinions of the physicians of the early Greek period. Following Hippocrates there were no medical writers of prominence until after the second century B. C. when Asclepiades had established Greek medicine on a firm footing in Rome.

During the first century A. D. and the reign of Augustus who patronized letters, Celsus, though probably not a physician but ranked with Hippocrates as one of the three greatest medical writers of antiquity, has given a masterly resume of medicine of his day in eight books which formed a part of his encyclopedia, and which by some strange fate are all that remains to us of that voluminous work. Aretaeus, who has been estimated as the most original and eloquent of medical writers of the classical period, has left us a most important work said to have been written somewhat later, during the reign of Nero, but the time in which he lived is in some doubt. Scarce a century passed and Galen of Pergamos made his brilliant career in Rome. His was a master mind and he gained such a preeminent reputation that, after Hippocrates, he has ever been regarded as the greatest physician of all time. He was a popular lecturer and wrote with clearness and commanding ability. His eclectic system of medicine appeared to be complete, the culmination of all possible, and his authority ruled all practice and remained undisputed for nearly 1500 years. He is reputed to be the first who sought direct evidence by experiment and adding something to the knowledge of the circulation and of neurology he has been called the "Father of Physiology." Several medical writers of antiquity have been accorded an English translation but it is a notable fact for which $I$ have not seen a sufficient explanation that Galen, notwithstanding his prominence and authority, has never been adequately translated for English readers. Only three small, partial and inconsiderable translations, two in the 17th century and a short epitome in the 19th, have appeared and these are so modest and obscure that they are scarcely known to librarians and not to booksellers. 
Medicine in Rome was largely in the hands of Greek physicians and upon the decline of the Empire, Hellenic traditions naturally prevailed. Of the Byzantine period which followed there are several writers of prominence whose works have been preserved and give an excellent review of the medicine of the time. The best known are Oribasius (4th century), a compiler rather than an original writer, who was charged by Julian, the Apostate, with the duty of making an abridgement of the works of Galen and "of reducing to a single volume all that the most illustrious physicians had taught, of utility, on the Healing Art'; Aetius (6th century), and Paul of Aegina (7th century). Most excellent English translations of the writings of Hippocrates, Aretaeus and Paul of Aegina are available, the work of that great classical scholar, Francis Adams, a busy practicing physician in the small and obscure Scotch village of Banchory.

During the several succeeding centuries medicine languished, fell into disrepute, and magic; sorcery, mysticism and the supernatural were cultivated and sought after. Greek writings had, however, been treasured and about the 9th century many of the manuscripts gathered at Constantinople were sent to Bagdad, that great centre of Saracen learning, where they were translated into Arabic and then into Latin, the universal language of literature and science. These manuscripts were later sent to the western world for the use of teachers and scholars and have been the principal source of our knowledge of the classical period. Utilizing the learning thus coming into the hands of the Orientals, the Arabian and Jewish school of medicine arose, introduced chemistry and pharmacy into practice and held sway for several hundred years, waning during the 12th century and yielding to the dominating influence of Greek culture. The principal writers of this school whose works have been preserved were, Rhazes (9th century), his work on measles and small-pox being a classic to this day; Avicenna, the "Prince of Physicians" (11th century); Albuscasis, the surgeon, (11th century); Averroes and Avenzoar (12th century). Large collections of medical and other manuscripts were made by the Arabians principally at Cairo, Tripoli and the cities of Spain. The library at Cordova is said to have contained 250,000 volumes in the 10th century and 600,000 in the 15 th, the catalogue at the latter date numbering 141 volumes. During this period learning and education were brought more and more within the control of the monasteries and throughout the middle ages intelligence and original thought were suppressed or subjugated and made subservient to religion and theological dogma. 
Some part at least of the Greek manuscripts were probably retained in Italy. Already in the 9th century before the influence of the Arabians and Jews had been felt in Europe the medical school at Salerno, following the traditions of Greek medicine, had gained great repute and attracted students from all parts of the continent. During the middle ages universities were established in other parts of Italy, elsewhere in Europe and in Great Britian, largely in opposition to the thraldom exercised by the narrow scholasticism of the monastic orders. All learning was restricted by that galling yoke during many centuries and only toward the end of the 15th when Europe was finally awakening to a new era of intellectual life did the rising tide of resentment among the choicer spirits, physicians and others, gain sufficient adherents and power to be courageously proclaimed and have effect.

Medicine received especial attention at the universities of Italy, particularly in those of northern Italy which is called the cradle of modern medicine, notably at Padua and Bologna. The learning and traditions fostered in Italy spread to other centers, to Montpellier and Paris in the 12th century, to Leyden in the 15 th and from there to Edinburgh, all of these schools gaining great renown. Throughout all this period and long after, the dictum of the classical authors reigned supreme and far more attention was given to the search for authority than to an original observation af facts.

With the invention of printing the works of the ancient and medieval authorities were published in many editions and made available for universities and a few physicians. According to late estimates not less than 1500 of the 28,000 to 30,000 incunabula were medical, though Hain mentions but 800 . Libraries were established by the various universities and these included medical works. Many of the hospitals and medical colleges both on the continent and in Great Britain made their own special collections, as St. Bartholomew's Hospital of London (1422), and the College of Physicians, London (1525). The library of the Faculté de la Médecine of Paris was established in the middle ages but in 1395, the date of the first register now in its possession, it had only twelve volumes. All books at that time were highly prized and jealously guarded as illustrated by the agitation caused by the application of Louis XI in 1471 for the loan of a copy of a work of Rhazes he wished to consult and copy. The Faculté after several meetings and much discussion granted his request but only after a rich merchant of Paris had become sponsor for the return of the book by the actual deposit of a large sum in gold and silver. In transmitting the work to the King the president sent 
with it a letter in which he emphasized the greatness of the favor and asked a subvention on account of the poverty of the institution. The book was returned the following year but the subvention was not allowed.

The 16th and 17th centuries, the golden age of literature, art and science-happily called the "May-time of science" - developed great men in medicine, anatomists, physiologists, microscopists, and others whose names are best known in connection with their achievements in other sciences, as chemistry and astronomy. The work of these pioneers in the science of medicine was of the utmost importance. The valorous spirit of devotion with which they pursued their investigations in new fields under such adverse circumstances that life itself was at stake and often sacrificed, must ever excite the admiration of all, and their accomplishments, which opened the way for all progress and form the corner stones of our present structure, demand our lasting gratitude. Their writings are extant and are the most cherished and revered assets of all libraries possessing them. I regret that I cannot dwell upon this most interesting period of development and consider with you those days of romance in science.

William Harvey stands out foremost of his time, not only because of his epoch making demonstration of the circulation of the blood which effected a revolution in medical thought and practice, but also as being the first to establish on a lasting basis the value of the experimental method in the study of medicine. Medical works were collected during this period by physicians as well as by hospitals and medical schools. Thomas Linacre (1460-1524), an eminent classical scholar, had a good collection of the medical books of that time, and Sir William Gilbert (1540-1603), physician to Queen Elizabeth, had a particularly valuable library which he left to the College of Physicians. Harvey in his 71 st year erected a fine library building in London to contain his large collection of books and specimens, furnished it handsomely and presented it to the same College. It was known as the "Museum of Harvey." Both of these collections were destroyed by the great fire of 1666 . Sir John Radcliffe (1650-1714) who in his student days boasted "that he did not prepare himself for the practice of the art of healing by what he considered an useless application to the rubbish of antiquity contained in musty volumes," left a bequest of forty thousand pounds to establish a library at Oxford still known by his name. The library of Richard Mead (1673-1754), said to have been one of the finest and most valuable of all private libraries of his time is an example of the usual fate of such libraries. At his death it was sold at auction and dissipated, yielding the sum of $£ 5,496$. 
Sir Hans Sloane (1660-1753), also a prominent London physician, made a more fortunate disposition of his library of 50,000 volumes which, with his other collections, were left to be sold to the Government, thus establishing the British Museum, now the largest and most valuable collection of books, manuscripts and relics of antiquity in the modern world.

The 18th century was characterized by its philosophies and the attempts to reduce all knowledge to systems, and activities in scientific research waned. A lively interest was still taken in all matters of science but it was that of the dilettante, not of the indefatigable, eager investigator. Medicine became the vogue in Paris, and ladies of high station amused themselves in dissecting rooms. Sydenham, called the English Hippocrates, in the latter half of the 17th century, Boerhaave, Haller, the "Prince of Scholars," and Cullen in the 18th were the most distinguished medical writers of their day.

With the close of the 18 th century and after a keener spirit of analysis had been evinced, definite evidences in confirmation or refutation of beliefs were more eagerly sought. Reference may here be made to the works of Morgagni, Auenbrugger, Bichat, Corvisart, Laennec and Louis. This spirit which developed in France more especially was caught up and intensified in Germany which then became the Mecca for medical students. Laboratories had been used for the teaching of anatomy and they were now established for other branches, the experimental method was extended and subsequent investigations gave important additions to our knowledge in physiology, histology and pathology. Searching examinations of fundamental questions in geology and the natural sciences were rigidly pursued and the resulting demonstrations led to the general adoption of the doctrine of evolution, which finally broke down the last remaining barriers that had held all science in leash. In the sixth decade of the last century, Pasteur determined the true nature of fermentation, and applying the principles then evolved soon demonstrated that germ life was the underlying cause of all infectious diseases. The door was thus opened for further intensive biological studies and marvelous successes followed in the prevention of the most deadly diseases and more direct and accurate methods were developed for diagnosis and treatment. The experimental method introduced by Galen and forgotten until utilized by Harvey, applied to the problems of biology and chemistry yielded far greater results for the science of medicine than all the previous observations and laborious studies of authority.

Learning has ever been dependent upon the written records of the past. Osler has called books the tools of the mind. During the 
middle ages they were exceedingly rare and costly, and libraries were at best comparatively small, notwithstanding the large number of rolls of manuscript credited to the Arabian collections. After the invention of printing, books were the form of record and it was not until 1536 in Venice that the first periodical appeared and then in sheet form. In 1679 the first medical periodical was issued in Paris, and two years later another, but both were short lived. In Germany in 1717 the first year-book appeared. During the 18th century many scientific societies were formed and their transactions were published. These contain the most important medical communications of that time. It was in transactions that Reamur published his observations on the digestion of birds, Priestly his isolation of oxygen, and Lavoisier announced oxygen, the interchange of gases in the lungs and the sources of animal heat. The journals of those days gave some current news and little else except observations with comments and reports of cases. At least one medical journal is still published in Germany which had its inception in the 18th century (Archiv für Physiologie, 1795) though it has changed the form of name several times. The first medical periodical in the United States, the Medical Repository, appeared as a quarterly in 1797 and was continued until 1824 . The Edinburgh Medical Journal, a continuation of the Annals of Medicine (1796), has appeared under practically the same title since 1805 . The London Lancet, established in 1823 by Thomas Wakley, has had the longest existence under one title. The oldest medical journal in the United States, also the most important throughout its career, the American Journal of Medical Sciences, has been published under this name since 1827 when it succeeded to the American Medical Recorder (1818) and the Philadelphia Journal of Medical Sciences. During the past half century, medical publications have increased enormously in number and volume. This increase has been mainly in the number and character of the medical journals, very many of which are devoted exclusively to the pure science of medicine, being the records of laboratory studies and research. Mr. Fisher, of the College of Physicians, has estimated that during the four years of 1909 to 1913, 225 medical journals were started and only 62 ceased publication. Today there are 1500 medical journals received regularly at the library of the Surgeon's General's office in Washington, approximately all that are published in the world, and this list does not include other forms of periodicals, as transactions, year-books, reports, etc. It is impossible to state with any accuracy the number of medical books published in any one recent year, the estimates varying greatly from 2,000 upwards. For the year 1913, actual figures for the United 
States, Great Britain, Germany, France, Italy and the Netherlands give a total of about 5,000 new books, not including new editions, and it should be noted that in this estimate many countries in which medical science is active are omitted.

Medical literature has ever found a welcome place in general libraries. Long experience, however, has shown that these collections tend to languish in that environment and are most successful and useful to the medical profession when conducted independently and by a special organization. The practitioner has long since learned that the facilities afforded by a private library are insufficient to keep abreast with modern medicine, and as his ranks are filled by men who have received the higher technical training of recent years, the need of medical libraries giving ample opportunities for reading and reference is becoming more urgent. The difficulties incident to the establishment of a general library are increased many fold in the building up of a medical library, which at best can have but a limited number of patrons. The growing demand on the part of the medical profession for library facilities is, however, overcoming these obstacles and new and vigorous medical library associations are springing up in the smaller communities, as in larger cities of the United States. In 1914 there were 312 medical libraries in the world. At the present time there are 174 medical libraries in the United States, probably more than fifty per cent. of the total number, and this is an increase from 60 in 1876, from 67 in 1898 . The great medical libraries of the world have had their very large proportionate growth and have been built up during the last forty years. The largest today, and the oldest, that of the Faculté de la Médecine of Paris, had accumulated but thirty-two volumes during the three and a half centuries of its existence to 1733 . It now has 240,000 volumes and is rich in incunabula, manuscripts of Arabian authors, and other ancient medical writings. The second in size, rich in incunabula, and works illustrating the history of medicine, unrivalled in practical usefulness, is that of the Office of the Surgeon General, U.S. Army, at Washington, with 220,202 volumes of which 60,000 are journals. The third in size is that of the Imperial Military Institute at Petrograd with 179,572 volumes. The library of the Pennsylvania Hospital, Philadelphia, was the first medical library to be established in the United States and this was started in 1762 by the gift of one book. Of the eight medical libraries which were established in the United States during the 18th century, only one, the College of Physicians of Philadelphia, has had a continuously active career, and attained large proportions. The largest and most important medical libraries in 
the United States in the order of size, excepting the one at Washington, are the College of Physicians, Philadelphia, (1787), with 107,782 volumes; the New York Academy of Medicine (1847) with 101,083 volumes; Boston Medical Library, (1875) 84,000; the Medical Society of the County of Kings, Brooklyn, (1845), with 70,000 volumns; John Crerar, Chicago, (1906), 66,000. Our library in Denver (1893) has about 17,000 volumns.

The literature of medicine is well indexed, better I believe than any other branch of literature. Schmidt's Jahrbücher, an abstract of important articles since 1834; the monumental Index Catalogue of the Surgeon General's Library in thirty large quarto volumes; and, the Index Medicus, a monthly analytical index of all medical journals of the world known to the Surgeon General's Office, established in 1879 , give the medical profession ready access to the older medical literature as well as that now current. Medical literature is essentially ephemeral and that of today is replaced by that of tomorrow. Twenty-five years ago Billings estimated that not one tenth of it is of value after ten years and the proportion is now probably still less. Text-books are usually the more or less well digested and condensed summary of the latest developments in medicine and an exposition of the best current opinion, but at the date of issue the text is often from six months to one or even two years behind advances noted in active subjects by late journals. Compendious reference works soon lose their freshness and both classes of books are being constantly pushed aside by the work of other authors or new editions. Books are in fact not in great demand and Mr. Fisher estimates that more than seventy-five per cent. of all calls in medical libraries are for journals. It is in journals, that we find the record of all recent developments, the monographs, and may follow the course of advance step by step.

The bulk and complexity of medical literature is increasing rapidly and it must have the best technical treatment if medical libraries are to maintain a proper degree of efficiency and make it readily available for reading and reference. Medical science is constantly developing new subjects and many new and strange words are being added to our terminology for which no definite place has been provided in some of the older classifications now in use and each librarian solves these problems according to his individual judgment. The principles of library science are now so well recognized that medical librarians should have no serious difficulty in agreeing upon a system of classification and notation best adapted to future as well as the present needs of our special department of literature. Such a 
system should be at once brief, expansive, elastic, and following the principles of mnemonics provide amply for intercalation of new subjects and their subdivisions. A system of classification and notation thus standardized for medical libraries, with prepared schedules and a list of approved subject headings would be of the greatest advantage to medical libraries as they are organized or reorganized and placed on a modern working basis as well as to the younger generation of medical librarians not yet fully conversant with the intricacies of our literature. This is a matter which may very properly engage the earnest attention of this Association. It has been considered many times before but in my judgment it should be taken up and pursued until an effective result is obtained. I believe this is an opportune time to study this subject again, and I beg to suggest that this Association should inaugurate and foster such a movement by the appointment of a committee which shall carefully consider various systems of classification and notation with a view to their adaptation to medical libraries, possibly in co-operation with a similar committee of the American Library Association and make a detailed report at a subsequent meeting.

Oliver Wendall Holmes has said "There is a dead medical literature, and there is a live one. All that is ancient is not dead, all that is live is not modern." Old medical works are of value for their historical interest; as being the product of some author distinguished in his time or as being the record of a discovery or a thought which has served as one of the stepping stones to progress. Such works have been carefully winnowed and there is a little left of value that has not been incorporated in our modern records and practice. Occasionally, however, a thought, a suggestion, a practice has been overlooked, forgotten or made in advance of a time when conditions were ripe for its application and some fortunate reader culls the golden fruit from obscurity and scores for betterment.

In all the foregoing remarks I have referred exclusively to the scientific aspect of our literature and its repositories. You well know that this is not all and I cannot close without referring to another and large class of medical literature, the cultural, the histories of medicine, the biographies of the distinguished men and heroes of our profession and the essays that throw so many side lights upon health, disease and practices, matters of the most intimate human concern that have engaged the attention of master minds of all ages. Medical men have contributed largely to general literature, as Rabelais, Smollett, Goldsmith, Crabbe, Schiller, Keats, Lever and latterly Holmes, Weir Mitchell and Conan Doyle to mention a few well known 
to all. Who among you have not read John Brown's pathetic tale of "Rab and His Friends"' which touches a sympathetic chord in every heart that makes all the world kin? Medicine has also been a fertile field for all classes of writers, philosophers, novelists, dramatists, satirists, and has been freely used in art and caricature. But these are phases of medical literature that cannot even be touched upon at present.

I shall have spoken in vain if I have not left with you an impression of the importance of the special treatment of medical literature. A library, particularly a medical library may be a simple repository, and

\footnotetext{
"Here the still air Broods over drowsy nooks Of ancient learning."
}

There is no library more dreary and useless than a medical library that is dormant, and if it is to be of use for a rapidly progressing science it must be an active workshop. There is an old Hindu saying "Truth like a stick, casts as many shadows as there are lights thrown upon it, yet in the light of Perfect Knowledge has it none. Man judges ever by shadows, "and of shadows is his knowledge built up; still of the essence of things he knows but nothing." Lessing tells us that the struggle for truth is the portion of humanity. The medical library furnishes the experience and wisdom for man's greatest good, his health and life, and it should be kept ever alert and ready to serve the best if not the latest information. It is a life work worthy of our efforts and in carrying it forward we may well call to mind the ancient word of instruction from the Talmud "The day is short and the work is great, and the reward is much and the master of the house is urgent. It is not thy duty to complete the work, but neither art thou free to desist from it."

\section{MINUTES OF THE 19th ANNUAL MEETING HELD AT DETROIT, JUNE 12, AND ANN ARBOR, MICHIGAN, JUNE 13, 1916. MONDAY, JUNE 12 .}

The 19th meeting of the Medical Library Association was called to order at $10.20 \mathrm{~A}$. M. in the Library of the Wayne County Medical Society, Detroit. In the absence of the President, Lieut. Col. C. C. McCulloch, Jr., and owing to the delay of the Vice-President, Dr. L. H. Taylor, Mr. C. Perry Fisher was elected provisional Chairman. In the absence of the Secretary, Dr. John Ruhräh, Miss M. C. Noyes, from the headquarters in Baltimore, was asked to serve as Secretary protem. There were over thirty members and guests present at the meeting. Some of those in attendance were: Miss Ethel L. Goff, 